\title{
REUTILIZAÇÃO DAS PASTILHAS DE PARAFORMALDEÍDO: AVALIAÇÃO DA SUA ATIVIDADE ESTERILIZANTE*
}

\author{
REUSE OF PARAFORMALDEHYDE TABLETS: EVALUATION OF THE \\ STERILIZING ACTIVITY
}

\section{REUTILIZACIÓN DE PASTILLAS DE FORMALDEÍDO: EVALUACIÓN DE SU ACTIVIDAD ESTERILIZANTE}

\author{
Kazuko Uchikawa Graziano** \\ Tamara Iwanow Cianciarullo*** \\ Terezinha de Jesus Andreoli Pinto****
}

Graziano KU, Cianciarullo TI, Pinto TJA. Reutilização das pastilhas de paraformaldeído: avaliação da sua atividade esterilizante. Rev Esc Enferm USP 2002; 36(2): 184-92.

\begin{abstract}
RESUMO
A atividade esterilizante das pastilhas de paraformaldeido reutilizadas foi avaliada por meio do monitoramento microbiológico, segundo a técnica da Association of Official Analytical Chemists (AOAC), exigida no Brasil para o registro desta categoria de saneastes junto à Vigilância Sanitária do Ministério da Saúde. Preliminarmente aos testes microbiológicos, foram realizados ensaios físico-quimicos por meio da titulometria iodométrica segundo a Society of Japanese Pharmacopeia que permitiram a construção de uma curva de concentração de formaldeído gasoso liberado por ciclo de esterilização, em relação ao número de reutilizações, subsidiando, desta forma, a escolha do momento da realização das análises microbiológicas. As pastilhas de paraformaldeido mantiveram atividade esterilizante na concentração de 3\% $\left(3 \mathrm{~g} / 100 \mathrm{~cm}^{3}\right)$ num periodo de exposição de $4 \mathrm{~h}$ à temperatura de $50^{\circ} \mathrm{C}$ sob umidade relativa máxima, após 12 ciclos de reutilizações de um mesmo grupo de pastilhas.
\end{abstract}

PALAVRAS-CHAVE: Paraformaldeído. Esterilização. Desinfecção. Infecção hospitalar.

\begin{abstract}
The sterilizing activity of reused Paraformaldehyde tablets was assessed by microbiologic monitoring according to the Association of Official Analytical Chemists (AOAC) technic required in Brazil to register this class of sanitizing substances into the Health Ministery. Previous to the microbiologic tests, physical-chemscs assays were done through iodine titration according to the Society of Japanese Pharmacopoeia. It was possible, than, to draw a graphic showing a curve of the gaseous formaldehyde concentration discharged, at each sterilization cycle in relation to the number of reuse of the paraformaldehyde tablets. Through this graphic it was possible to chose the adequate moment to make the microbiologic analysis. After 12 cycles, the some group of the paraformaldehyde tablets kept the sterilizing activity at 3\% concentration $\left(3 \mathrm{~g} / 100 \mathrm{~cm}^{3}\right)$, at $50^{\circ} \mathrm{C}$, for 4 hours of exposition time with great relative humidity.
\end{abstract}

KEYWORDS: Paraformaldehyde. Sterilization. Desinfection. Cross infeccion.

\section{RESUMEN}

La actividad esterilizante de las pastillas de paraformaldeido, reutilizadas, fué evaluada por medio de control microbiológico, según la técnica de la Association of Official Analytical Chemists (AOAC), exigida, en Brasil, por la Unidad de Vigilancia Sanitaria del Ministerio de Salud. Preliminarmente, se realizaron ensayos físicoquimicos por medio de la titulometria yodométrica, según la Society of Japanese Pharmacopeia, que permitieron la construcción de una curva de concentración de formaldeído gaseoso, liberado por ciclo de esterilización, en relación al número de reutilizaciones, y subsidios para la elección del momento de realización de los andlisis microbiológicos. Las pastillas de paraformaldeido mantuvieron actividad esterilizante en una concentración del $3 \%(3 \mathrm{~g} / 100 \mathrm{~cm} 3)$ en un periodo de exposición de 4 horas a una temperatura de $500 \mathrm{C}$ sometida a humedad relativa máxima, después de 12 ciclos de reutilizaciones del mismo grupo de pastillas.

PALABRAS CLAVE: Paraformaldeído. Esterilización. Desinfección. Infeccion hospitalaria.

ë.. Artigo extraído de: Graziano KU. Reutilização das Pastilhas de Paraformaldeido: avaliação da sua atividade esterilizante. São Paulo, 1995. 9'7p. Tese (Doutorado) - Escola de Enfermagem, Universidade de São Paulo.

Professor Associado do Departamento de Enfermagem Médico-Cirúrgica da Escola de Enfermagem da Universidade de São Paulo, e-mail: rwgraziano@uol.com.br.

Professor Titular do Departamento de Enfermagem Médico-Cirúrgica da Escola de Enfermagem da Universidade de São Paulo. Farmacêutica. Professor Titular da Faculdade de Ciências Farmacêuticas da Universidade de São Paulo. 


\section{INTRODUÇÃO}

O avanço da tecnologia na área odonto-médicohospitalar, por meio de uma constante busca de inovações e progressos, produziu, como resultado, múltiplos produtos termossensiveis utilizados em materiais de prótese, de cateterismo e de endoscopia, assim como de componentes elétricos.

Neste contexto, a esterilização gasosa foi introduzida nos hospitais como um método capaz de garantir a segurança do processo de esterilização, visando não apenas a preservação da integridade daqueles materiais, mas principalmente a sua esterilidade.

O gás óxido de etileno ainda ocupa uma posição de destaque como um método de escolha para a esterilização de artigos termossensiveis, porém, com vários inconvenientes. Destacam-se, entre eles, a absorção e a adsorção do gás residual nos materiais e a sua toxicidade ambiental, sendo o processo condenado dentro dos hospitais ${ }^{(1)}$. Indiscutivelmente, o óxido de etileno é hoje reconhecido como um agente químico extremamente perigoso pelo seu caráter mutagênico, que afeta a segurança dos trabalhadores e cujos riscos não devem ser subestimados.

Novas tecnologias mais adequadas ao processamento dos artigos termossensiveis vêm sendo desenvolvidas nas últimas décadas, como esterilizadores por plasma de peróxido de hidrogênio $\left(\right.$ Sterrad $\left.^{\mathbb{}}\right)$, bem difundidos em nosso meio; autoclave de vapor de baixa temperatura e formaldeído, esterilizadores à base de ácido peracético (Steris ${ }^{\circledR}$ ) $\mathrm{e}$ do sistema combinado vapor de ácido peracético e gás plasma (AbTox Plazlyte $\left.{ }^{\circledR}\right){ }^{(2)}$.

Apesar desse avanço, o Brasil, indiscutivelmente um país de muitas desigualdades e contrastes, apresenta grande heterogeneidade no que se refere aos recursos disponiveis para a esterilização. Algumas vezes, hospitais que executam técnicas cirúrgicas sofisticadas, como por exemplo artroplastia total de quadril, convivem com a total falta de condições seguras para a esterilização dos artigos termossensiveis.

É neste cenário que surgem as Pastilhas de Paraformaldeído como agente químico esterilizante, que apesar dos muitos problemas no seu uso quando comparadas a outros métodos, algumas vezes são o único recurso disponivel.

A revisão da literatura sobre as formas de utilização do Paraformaldeído, como agente esterilizante, em condições ambientais (sem o uso de equipamento específico), indica que não existe um consenso entre os vários autores, o que pode ser atribuído à diversidade de metodologias de análises empregadas. Sabe-se que não há, até o momento, uma metodologia oficial de avaliação de agentes químicos antimicrobianos aceita universalmente( ${ }^{(3)}$. Os Estados Unidos foram os pioneiros na padronização de métodos, seguidos pelo Reino Unido, Alemanha, Holanda e França. Em alguns países foram estabelecidas as definições e os critérios, mas os testes não foram propostos. Em 1985, o Ministério da Saúde do Brasil adotou como metodologia oficial de análise para aprovação de agentes químicos esterilizantes a dos Estados Unidos, que segue a preconizada pela Association of Official Analytical Ohemists-AOAC. Assim, os diferentes autores estabelecem parâmetros divergentes para a esterilização de superficie dos artigos por meio das Pastilhas de Paraformaldeído, utilizando diversos métodos de análise como Salzano(4) que chegou à conclusão de que o paraformaldeído, quando colocado na estufa a $50^{\circ} \mathrm{C}$, por um período de exposição de duas horas e numa concentração de $5 \%$, esteriliza o material cirúrgico previamente limpo e seco; Schilling(5) que chegaram à conclusão que a esterilização de materiais requer 10 tabletes por $\mathrm{dm} 3$ do volume do recipiente, com tempo de exposição de 15 a 24 horas, sem submeter os materiais ao aquecimento além da temperatura ambiente, com umidade relativa de $80 \%$; Martindale(6) que faz referências sobre a ação esterilizante do paraformaldeído a $0,1 \%$ e $0,15 \%$ à temperatura de $16^{\circ} \mathrm{C}$, cobrindo o recipiente com uma camada de gaze levemente úmida e Cunha, Almeida e Mimica(7) que estudaram a ação microbicida do paraformaldeído a $1 \%$ à temperatura ambiente e mostraram que após 8 horas de exposição o material encontrava-se esterilizado.

Os parâmetros seguros para a esterilização em condições ambientais utilizando as Pastilhas de Paraformaldeído foram pesquisadas por Graziano(8), que seguiu a metodologia da AOAC oficialmente adotada pelo Ministério da Saúde do Brasil(9). Os resultados indicaram a necessidade de uma concentração do agente químico de $3 \% \quad(3 \mathrm{~g}$ de Pastilhas de Paraformaldeído para cada $100 \mathrm{~cm}^{3}$ do volume do recipiente - em nosso meio, a apresentação comercial das pastilhas é de $0,5 \mathrm{~g} /$ pastilha); temperatura da estufa regulada nos $50^{\circ} \mathrm{C}$ (sendo os artigos termossensiveis compativeis com esta temperatura); tempo de exposição de 4 horas (a partir do momento da colocação do material na estufa préaquecida àquela temperatura) e umidade relativa de $100 \%$ (obtida com a colocação de um chumaço de algodão molhado com 3-5 ml de água destilada num recipiente). Sem a garantia da penetrabilidade através dos artigos, mas restrigindo-se à sua superficie, constatou-se nesse estudo a efetividade da esterilização frente aos esporos do B.subtilis ATCC 19659 e C.sporogenes ATOC 3584 quando os penicilindros (carreadores de porcelana dos microrganismos testes) que foram contaminados com aqueles microrganismos apresentaram 480 culturas negativas. 
Dentro da prática do uso das pastilhas de paraformaldeído como agentes antimicrobianos, destaca-se a sua reutilização empírica. Assim, um mesmo conjunto de pastilhas é utilizado por diversas vezes sem que haja um critério norteando essa ação.

Em aulas e palestras, ao serem questionados sobre o processo de reutilização, os usuários geralmente referem-se a eles como: reutilizam as pastilhas enquanto elas se apresentam íntegras ou enquanto mantêm-se exalando o odor característico...

Certamente, a prática da reutilização não é executada apenas por questões econômicas, visto que o custo das pastilhas de formaldeído é significativamente mais baixo quando comparado com o custo de outros processos de esterilização, mas induzida pelo fato de que o desgaste das pastilhas é considerado imperceptivel pelos usuários, mesmo após vários ciclos de processamentos.

Levando-se em conta o resultado dos estudos dos autores citados, onde as condições definidas para fundamentar a utilização das pastilhas de paraformaldeído como agente esterilizante estabelecem uma proporção entre o peso das pastilhas e o volume do recipiente onde o material será processado, infere-se numa primeira análise que a reutilização das pastilhas não é recomendável, uma vez que em cada ciclo de esterilização ocorre redução na massa das pastilhas pela sublimação das mesmas em vapores de formaldeído.

Nas buscas bibliográficas foram encontradas duas citações sobre a possibilidade de reutilizar a mesma fonte geradora do formaldeído gasoso. Shilling(5) ao pesquisarem sobre o uso de pastilhas de paraformaldeido para a desinfecção, esterilização a frio e redução da probabilidade de contaminação durante o armazenamento de equipamentos e instrumental esterilizados em armários "HEYNEMANN", recomendavam que as pastilhas fossem espalhadas no armário, numa quantidade de uma por $\mathrm{dm}^{3}$ e que se promovesse a sua troca a cada 2 ou 3 semanas, de acordo com o número de vezes em que o armário fosse aberto. Hennnebert, Gillard e Roland(10) quando propuseram a construção de um equipamento por formaldeído gasoso, citaram no item de produção e esterilização da fase gasosa de formaldeído, que 3 litros de solução de formalina eram usados como fonte geradora do gás e que muitos ciclos de esterilização puderam ser feitos com a mesma solução sem que se tivesse perdido a eficácia.

Estas colocações do problema, definiram a necessidade do estudo relacionado à segurança na reutilização das pastilhas de paraformaldeído para subsidiar a prática de esterilização utilizando esse agente químico em nosso meio.

\section{OBJETIVO}

Avaliar a ação esterilizante das pastilhas de paraformaldeído reutilizadas, nas condições de esterilização definida por Graziano ${ }^{(8)}$ de $3 \%(\mathrm{~m} / \mathrm{v})$, a $50^{\circ} \mathrm{C}$ por $4 \mathrm{~h}$ de exposição, sob umidade relativa máxima, por meio do monitoramento microbiológico realizado segundo a técnica da AOAC, na tentetiva de estabelecer um número seguro de reutilizações.

\section{MATERIAL E MÉTODO}

Na primeira etapa da pesquisa foi realizada a mensuração da concentração do formaldeído gasoso liberado no recipiente pelas pastilhas reutilizadas, após cada ciclo de 4 horas a $50^{\circ} \mathrm{C}$ com umidade relativa máxima, condições essas estipuladas como requisitos para a esterilização, no trabalho de avaliação da atividade esterilizante do Paraformaldeído de Graziano (8)

Assim, obteve-se um panorama do comportamento das pastilhas de paraformaldeído durante o processo de reutilização, frente às condições de esterilização, por meio da construção de uma curva de concentração do formaldeído gasoso liberado por ciclo, em relação ao número de reutilizações.

Com base nessa curva, na segunda fase do trabalho determinou-se o momento em que as análises microbiológicas deveriam ser realizadas, para validar ou não a reutilização das pastilhas de paraformaldeído e ao mesmo tempo estimar um número seguro de reutilizações de um mesmo grupo de pastilhas.

Para a análise química da concentração do formaldeído gasoso liberado nas reutilizações das pastilhas, foi escolhida a titulometria iodométrica segundo a Society of JapanesePpharmacopeia(11).

A metodologia escolhida para a análise microbiológica foi aquela adotada oficialmente pelo Ministério da Saúde do Brasil, no registro dessa categoria de saneadas antes e domissanitários junto à Vigilância Sanitária que estabelece a metodologia da AOAC, já utilizada por Graziano (8) no estudo anterior que avaliou a atividade esterilizante das pastilhas de Paraformaldeído.

\section{Análises físico-quimicas}

\section{Coleta do formaldeído gasoso}

Para possibilitar a coleta do material gasoso na primeira etapa do trabalho, foram preparados recipientes de aço inoxidável (caixas A, B e C) de 720 $\mathrm{cm} 3$ de volume (comprimento $=18 \mathrm{~cm}$, largura $=8$ $\mathrm{cm}$, altura $=5 \mathrm{~cm}$ ) em cuja tampa foi adaptada uma via de saída para o formaldeído gasoso liberado pelas 
pastilhas contidas em seu interior. Uma extensão plástica com $50 \mathrm{~cm}$ de comprimento conectada a essa via de saída conduziu o formaldeído gasoso liberado para um frasco Kitassato em cuja tampa foi passado um tubo de vidro com a extremidade distal imersa em $100 \mathrm{ml}$ de água destilada, a fim de que o formaldeído gasoso fosse dissolvido nesse meio aquoso. Um filtro de Millipore HAWP 0,25 de difluoreto de polivinilideno de 0,45 Am de diâmetro foi posicionado entre a extensão e o frasco Kitassato, para reter partículas de paraformaldeído que eventualmente pudessem ser aspiradas juntamente com o gás, acarretando superestimativa na dosagem do formaldeído gasoso liberado por cada ciclo de esterilização.

$\mathrm{Na}$ via lateral do frasco Kitassato foi conectada a extensão da bomba de vácuo Millipore Waters modelo V115 para gerar pressão negativa no frasco de 10 - $15 \mathrm{pol} / \mathrm{Hg}$ (240 - $380 \mathrm{mmHg})$.

A fim de garantir a aspiração de todo o gás liberado num ciclo de esterilização, foi adaptado um sistema de respiro no recipiente de aço inoxidável, colocando-se uma rolha de borracha num orificio feito na tampa. Esse dispositivo possibilitou a execução de "lavagens" do ar no interior do recipiente e garantir o máximo de arrasto do formaldeído gasoso liberado.

Para submeter as pastilhas de paraformaldeído aos ciclos de esterilização, 22g dessas pastilhas (equivalente à concentração de 3\%), do mesmo lote de fabricação, foram acondicionadas nas caixas de aço inoxidável. As pastilhas foram dispostas no terço médio do comprimento da caixa e, nos terços distais da caixa, foram colocados dois chumaços de algodão em recipiente plástico, um de cada lado, embebidos com $5 \mathrm{ml}$ de água destilada e em cada processo de esterilização, certificou-se o embebimento deles para garantir a umidade relativa máxima dentro do recipiente durante o ciclo de esterilização.

Preparadas dessa forma, as caixas foram lacradas em toda a sua volta com fita de papel crepe e pingadas as extensões plásticas conectadas às vias de saída e submetidas ao ciclo de esterilização de $50^{\circ} \mathrm{C}$ por $4 \mathrm{~h}$. Depois disso, o gás acumulado no recipiente foi aspirado por um tempo total cronometrado de 2 minutos e 30 segundos. O primeiro minuto foi de aspiração contínua e o restante do tempo foi intercalado de 15 segundos de injeção de ar através do respiro, por uma agulha hipodérmica $25 \times 10 \mathrm{~mm}$ na rolha de borracha, com 15 segundos de aspiração de gás. O objetivo deste procedimento foi de conseguir o máximo de aspiração do formaldeído gasoso liberado no ciclo e imediata dissolução em $100 \mathrm{ml}$ de água contido no frasco coletor de Kitassato.

\section{Análise da solução de formaldeído}

A solução aquosa de formaldeído foi analisada por titulometria iodométrica, segundo metodologia descrita na Farmacopéia Japonesa(11) que permite detectar formaldeído com maior sensibilidade em relação a outras metodologias titulométricas.

Foram pipetados $50 \mathrm{ml}$ da solução de formaldeído a ser analisada para um frasco tipo iodo. Em seguida foram acrescentados $10 \mathrm{ml}$ de hidróxido de potássio TS e $20 \mathrm{ml}$ de iodo $0,1 \mathrm{~N}$ e o frasco tampado foi deixado em repouso por 5 minutos ao abrigo da luz. Após esse tempo, foram acrescentados $5 \mathrm{ml}$ de ácido clorídrico diluído, tampando-se imediatamente o frasco e deixando-se em repouso por mais 15 minutos ao abrigo da luz. Passado esse período, o excesso de iodo foi titulado com tiossulfato de sódio 0,1 $\mathrm{N}$ adicionando-se o indicador amido TS 0,3\% quando a solução apresentava-se com a coloração levemente acastanhada e a titulação prosseguiu até a viragem da cor da solução de violeta para incolor.

O doseamento do formol, pelo método iodométrico, processou-se pela oxidação do formaldeído para ácido fórmico pela solução alcalina de iodo. Como agente oxidante atuou o hipoiodeto formado na solução alcalina por meio da reação de desproporcionamento. $\mathrm{O}$ hipoiodeto não consumido formou novamente o iodo, por meio de acidificação, que foi identificado com o tiossulfato de sódio.

Para cada análise, foi feito um ensaio em branco, ou seja, utilizando-se os mesmos reagentes, sem o formaldeído, determinando-se a quantidade de tiossulfato de sódio $0,1 \mathrm{~N}$ consumida pelo iodo para que possibilitasse a determinação do diferencial do consumo de iodo enquanto houvesse formaldeído presente na solução .

Por essa metodologia, a cada $\mathrm{ml}$ de iodo $0,1 \mathrm{~N}$ consumido corresponderam a $1,5013 \mathrm{mg}$ de formaldeído presente na solução.

A determinação da quantidade do formaldeído na solução analisada foi feita segundo o cálculo:

(B - a) X 1,5013 X fc X 2 = Y mg/100ml de formaldeído, onde,

$\mathrm{B}=$ volume de tiossulfato de sódio $0,1 \mathrm{~N}$ consumido com o ensaio branco

$\mathrm{a}=$ volume de tiossulfato de sódio $0,1 \mathrm{~N}$ consumido com a amostra

1,5013 = miliequivalente do formaldeído

$\mathrm{fc}=$ fator de correção do tiossulfato de sódio $0,1 \mathrm{~N}$ analisada

2 = fator de diluição da amostra

$\mathrm{Y}=$ quantidade de formaldeído na solução

Foram colhidas duas amostras diárias, consecutivamente, sendo uma após o ciclo de esterilização no período da manhã $(8 \mathrm{~h}-12 \mathrm{~h})$ e a outra após o ciclo no período da tarde (12h 30min - $16 \mathrm{~h}$ 30min). 0 intervalo de tempo de "repouso" das 
pastilhas de um dia para o outro, à temperatura ambiente, foi em média de $15 \mathrm{~h} 30 \mathrm{~min}$. A cada 5 dias o intervalo de tempo foi maior, em torno de 63h 30min correspondentes aos finais de semana.

Antes da primeira exposição de cada dia, das pastilhas de formaldeído às condições de esterilização, o gás desprendido no intervalo de $15 \mathrm{~h} 30 \mathrm{~min}$ ou no de $63 \mathrm{~h}$ 30min era aspirado e dosado pressupondo-se que esta liberação do gás correspondia a uma perda da massa do paraformaldeído.

A interrupção das análises químicas do formaldeído gasoso, liberado pelas pastilhas reutilizadas, aconteceu após evidências conclusivas quanto ao comportamento das pastilhas de paraformaldeído durante as reutilizações.

Análises físico-quimicas das pastilhas de paraformaldeído após os processos de reutilizações

Após o término das dosagens da concentração de formaldeído gasoso liberada nas reutilizações, todas as pastilhas pertencentes a cada uma das caixas (A, B , C) foram pesadas e maceradas para análise quanto à quantidade de formaldeído remanescente, por meio da titulometria iodométrica, calculando-se também a umidade absorvida pelas pastilhas durante os vários processos de esterilização a que foram submetidas, utilizando-se o método de Karl Fischer( $\left.1^{2}\right)$. Tal método consiste na determinação de água por uma titulação iodométrica do tipo "dead stop" (ponto morto), por meio de um reagente especial constituído essencialmente de iodo e dióxido de enxofre. Na presença de água, o dióxido de enxofre é oxidado a ácido sulfúrico pela ação do iodo conforme a reação:

$\mathbf{S O}_{2}+\mathbf{I}_{2}+2 \mathrm{H}_{2} \mathrm{O}$ $>2 \mathrm{HI}+\mathrm{H}_{2} \mathrm{SO}_{4}$

Após toda a água ter reagido, o iodo livre, em excesso, permanece na solução e provoca uma brusca modificação na coloração da solução, indicando o ponto final, com exatidão.

\section{Análises microbiológicas}

Procedimento do desgaste das pastilhas novas de para formaldeido

Para a segunda fase dos experimentos, que consistiu nas análises microbiológicas visando estudar a ação esterilizante das pastilhas de paraformaldeído reutilizadas, por meio da metodologia da AOAC, grupos de pastilhas a $3 \%$ foram submetidas a ciclos idênticos aos já descritos de $50^{\circ} \mathrm{C}$ por $4 \mathrm{~h}$ com umidade relativa máxima com o objetivo de se obter pastilhas em condições similares àquelas correspondentes ao processo de análise da $\mathbf{1}^{\mathrm{a}}$ fase (3.1.1 e 3.1.2).

Para tanto, 8 recipientes de alumínio de $792 \mathrm{~cm} 3$ de volume interno foram preparados, nos mesmos moldes dos recipientes de aço inoxidável utilizados nas análises químicas e submetidos a ciclos de $4 \mathrm{~h}$ a $50^{\circ} \mathrm{C}$, umidade relativa máxima e com $3 \%$ de pastilhas

de paraformaldeído. Entre um ciclo e outro, os recipientes foram abertos numa capela com exaustão, para eliminação do formaldeído gasoso acumulado durante o processo. Os recipientes permaneceram abertos de 5 a 10 minutos, e após a verificação da necessidade ou não da hidratação dos chumaços de algodão, os recipientes voltavam a ser lacrados com fita de papel crepe em toda a sua volta e submetidos ao novo processo preconizado para esterilização.

\section{Microrganismos testes}

Os microrganismos testes indicados pela metodologia são: 19659)

Bacillus subtilis INOQS* $n^{\circ} 02\left(\right.$ ATOC $^{* *} n^{\circ}$

Clostridium sporogenes INOQS* $n^{\circ} 04$ $\left(\mathrm{ATCC}^{* *} \mathrm{n}^{\circ} 3584\right)$

As culturas estoques de Bacillus subtillis foram mantidas em ágar nutriente inclinado e a do Clostridium sporogenes em caldo extrato de ovo, carne e solo, à temperatura de $2^{\circ} \mathrm{C}$ a $5^{\circ} \mathrm{C}$, fazendo-se repiques mensais, com incubação por 72 horas a $37^{\circ} \mathrm{C}$. Ambos os microrganismos testes foram adquiridos da bacterioteca da Universidade Federal do Rio de Janeiro. A partir das culturas estoques, foram inoculados tubos com caldo nutriente extrato de solo para Bacillus subtillis e com caldo extrato de ovo, carne e solo para Clostridium sporogenes. A incubação foi por 72 horas a $37^{\circ} \mathrm{C}$. Essas suspensões de microrganismos continham aproximadamente $10^{6}$ a $10^{7}$ unidades formadoras de colônias (ufc) por $\mathrm{ml}$.

\section{Meios de subcultura}

Foi empregado meio de tioglicolato fluido, segundo a United States Pharmacopoeia XX com 0,1\% de sulfito de sódio como neutralizante do formaldeído.

\section{Carreadores}

Foram utilizados como carreadores, os penicilindros de porcelana com $8 \pm 1 \mathrm{~mm}$ de diâmetro externo, $6 \pm 1 \mathrm{~mm}$ de diâmetro interno e $10 \pm 1 \mathrm{~mm}$ de comprimento, adquiridos da Fisher Scientific Co., $\mathrm{n}^{\circ}$ 7907. Os penicilindros foram primeiramente lavados com o detergente Triton X diluído (1:100), rinsados em água corrente e consecutivamente em água destilada, esterilizados por autoclavação e secados em estufa antes do uso.

\section{Procedimento}

Os carreadores foram mergulhados na cultura teste do Bacillus subtillis e Clostridium sporogenes, na proporção de $1 \mathrm{ml}$ para cada carreador, 
sendo utilizados 120 carreadores de porcelana (penicilindros) para cada microrganismo teste. Após um período de contato de 10 a 15 minutos, à temperatura ambiente, os carreadores foram removidos para placas de Petri esterilizadas, contendo 2 folhas de papel de filtro para drenagem do líquido. Os carreadores foram depositados separadamente uns dos outros, numa média de 30 por placa. Em seguida, as placas contendo os carreadores contaminados foram transportadas para o dessecador a vácuo contendo sílica gel no qual foi aplicado vácuo de $69 \mathrm{cmHg}$ $(27 " \mathrm{Hg})$ durante 20 minutos. Os carreadores, assim dessecados, foram mantidos sob vácuo por $24 \mathrm{~h}$ para a secagem. Segundo a metodologia da AOAC, esporos secos, nessas condições, resistem 7 dias ou mais, sendo que nesses experimentos, os carreadores contaminados com esporos foram utilizados até no máximo 3 dias após dessecação e secagem.

Certos gases esterilizantes requerem a hidratação dos esporos antes da exposição a eles. Sendo esse o caso do formaldeído, os esporos contidos nos carreadores foram umidificados por imersão em água destilada, estéril, utilizando-se no máximo $20 \mathrm{ml}$ para um grupo de 6 carreadores. Após esse procedimento, os carreadores foram drenados por 20 minutos, em placas de Petri forradas com papel de filtro previamente esterilizados.

O contato entre pastilhas de paraformaldeído reutilizadas e carreadores contaminados com esporos de cada microrganismo teste foi feito nos mesmos recipientes de aluminio, onde foi processado o desgaste das pastilhas.

As pastilhas foram colocadas diretamente nos recipientes de alumínio, e os carreadores contaminados e hidratados foram colocados em placas de Petri esterilizadas. Após a vedação com fita crepe, os recipientes foram submetidos a $50^{\circ} \mathrm{C}$ por $4 \mathrm{~h}$ em estufa regulada.

Imediatamente após o período de exposição, cada carreador foi transferido para tubos de subcultura com $15 \mathrm{ml}$ do meio tioglicolato fluido com $0,1 \%$ de sulfito de sódio. Após a agitação do tubo, os carreadores foram removidos para um segundo tubo com o mesmo meio de cultura ( $2^{a}$ subcultura). Os tubos das duas séries $\left(1^{\mathrm{a}}\right.$ e $2^{\mathrm{a}}$ subcultura) foram incubados a $37^{\circ} \mathrm{C}$ por 21 dias, sendo então observada a presença ou a ausência de crescimento dos microrganismos.

Nos tubos onde ocorreu o crescimento (presença de turbidez), foram realizados estudos micromorfológicos após coloração pelo método de Gram Adicionalmente, o acompanhamento das características inerentes ao crescimento microbiano em cada tubo, durante todo o período de incubação, permitiram distinguir a sobrevivência dos microrganismos testes frente à contaminação acidental.
Os tubos com carreadores, onde não foi observado o crescimento (ausência de turbidez), foram submetidos a um choque térmico durante 20 minutos a $80^{\circ} \mathrm{C}$ e reincubados por 72 horas a $37^{\circ} \mathrm{C}$, registrandose então os resultados finais como: $(+)$ crescimento (-) ausência de crescimento.

\section{Controle positivo}

O controle positivo consistiu, neste trabalho, em recurso visando garantir a esporulação dos microrganismos e as condições de viabilidade dos mesmos, permitindo a validação do método empregado. Para tanto, 4 carreadores contaminados com esporos dessecados foram colocados em um tubo de ensaio contendo $10 \mathrm{ml}$ de ácido clorídrico $(\mathrm{HCl}) \quad 2,5 \mathrm{~N}$ esterilizado, resfriado e mantido a $20^{\circ} \mathrm{C}$ em banhomaria. Após 2, 5, 10 e 20 minutos de contato com o ácido, cada carreador foi retirado e transferido para cada um de quatro tubos com meio de tioglicolato fluido modificado (tioglicolato fluido com $2 \%$ de solução de hidróxidon de sódio- $\mathrm{NaOH} 1 \mathrm{~N}$ como neutralizante do $\mathrm{HCl}$ ). Após a agitação, os carreadores foram transferidos para outra série de tubos com o mesmo meio de tioglicolato fluido modificado (2a subcultura) e incubados por 21 dias a $37^{\circ} \mathrm{C}$.

Dois carreadores contaminados e dessecados foram colocados diretamente, um no tubo de subcultura contendo meio de tioglicolato fluido modificado e o outro no tioglicolato fluido com sulfito de sódio. Esse controle adicional permitiu que se certificasse a capacidade promotora de crescimento dos meios de cultura nas condições do trabalho.

\section{Interpretação dos resultados}

A atividade esterilizante só pode ser confirmada se não ocorrer crescimento algum nos 240 tubos de la e 2 a subculturas de cada microrganismo teste.

Para a confiabilidade do inóculo utilizado, os esporos devem resistir ao $\mathrm{HCl} 2,5 \mathrm{~N}$ por 2 minutos no mínimo, podendo até resistir por mais de 20 minutos.

A germinação deve ocorrer nos tubos onde os carreadores contaminados foram inoculados diretamente nos meios de subcultura utilizados (tioglicolato fluido com $0,1 \%$ de sulfito de sódio e tioglicolato fluido modificado) confirmando sua condição de adequacidade como meios de cultura para Bacillus subtilis e Clostridium sporogenes. 


\section{APRESENTAÇÃO E DISCUSSÃO DOS RESULTADOS}

\section{Análises físico-químicas}

O gráfico 1 mostra os niveis de concentração do formaldeído gasoso liberado pelas pastilhas de paraformaldeído das caixas A, B e C no decorrer das 47 reutilizações às quais as pastilhas foram submetidas e acompanhadas.

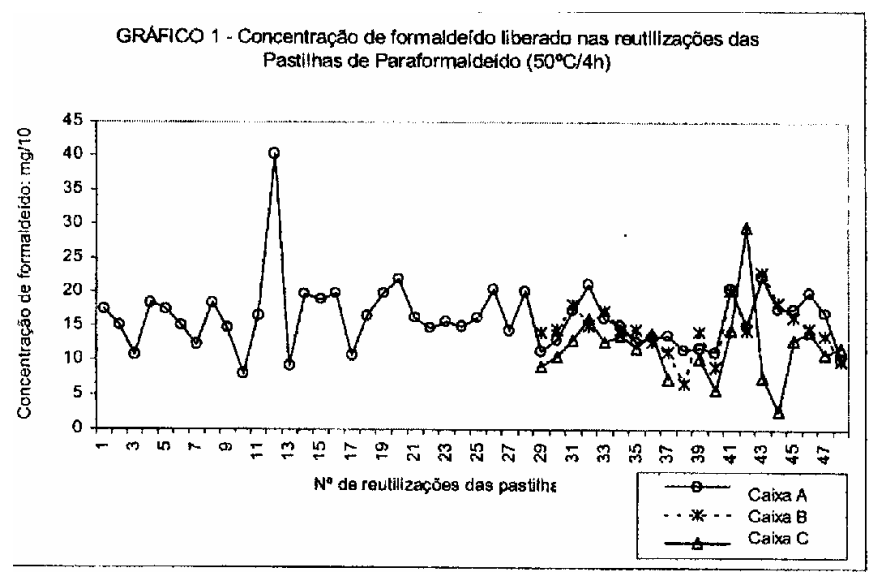

A interrupção das análises físico-químicas das pastilhas de paraformaldeído reutilizadas, deu-se após 47 reutilizações do mesmo grupo de pastilhas da caixa A, e após 19 reutilizações das caixas B e C por se ter considerado que a concentração do formaldeído gasoso liberado pelas pastilhas reutilizadas em cada ciclo de esterilização já estudada não apresentava grandes diferenças em relação às novas. Somado a isso, houve evidências de alterações das características físicas das pastilhas, com início de desintegração, o que coincide com um dos critérios para o limite de reutilizações das pastilhas pelos usuários desse agente químico.

Os resultados das análises físico-químicas das pastilhas de paraformaldeído, após os processos de reutilizações das caixas $\mathrm{A}, \mathrm{B}$ e $\mathrm{C}$, estão resumidos na Tabela 1:

Tabela 1 - Resultados das análises físico-químicas das Pastilhas de Paraformaldeído, após os processos de reutilizações das caixas A, B e C. São Paulo, 1992.

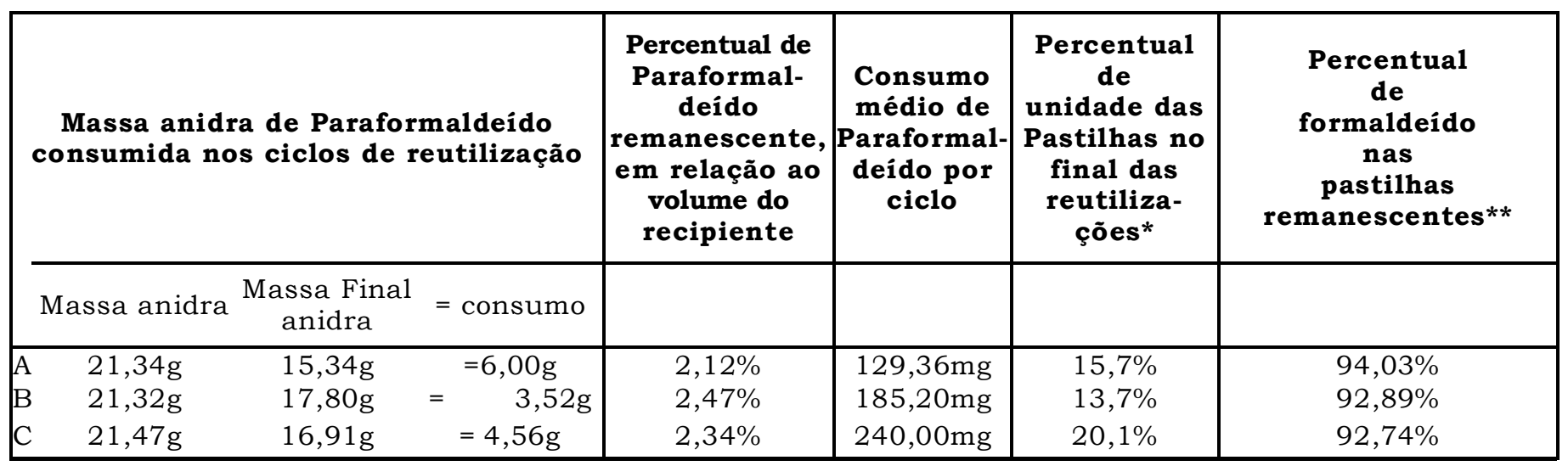

* Percentual de umidade das pastilhas novas: 3,0\%

** Percentual de formaldeído nas pastilhas novas: $96,18 \%$

A análise dos resultados apresentados na Tabela 1 permite concluir que o consumo da massa anidra do paraformaldeído nos vários ciclos de esterilização foi mínimo em relação à massa inicial anidra. As pastilhas da caixa A, que se submeteram a 47 reutilizações, conservaram um percentual de paraformaldeído remanescente que correspondeu a $2,12 \%$ em relação ao volume do recipiente.

Quanto ao percentual de formaldeído nas pastilhas remanescentes, os teores mantiveram-se próximos às pastilhas novas $(96,18 \%)$, apesar da redução da massa total das mesmas (massa inicial anidra - massa final anidra).

\section{Fase 2: Análises microbiológcas}

A opção pelo início das análises microbiológicas recaiu num primeiro momento sobre o número máximo de reutilizações que as pastilhas haviam sido acompanhadas na fase 1 dos trabalhos de análises fisico-químicas, ou seja, 47 reutilizações.

Apesar de se considerar esse número de reutilizações exagerado, tendo como parâmetro os referenciais práticos de esterilização utilizados pelas enfermeiras dos Centros de Materiais, resolveu-se mantê-lo, pelo fato de ter sido um dado fornecido nos testes fisico-químicos. 
As tabelas 2 e 3 apresentam os resultados dos experimentos microbiológicos.

Tabela 2 - Atividade esporicida das pastilhas de paraformaldeído a 3\% reutilizadas 47 vezes sobre de esporos de Bacillus subtilis à temperatura de $50^{\circ} \mathrm{C}$ por $4 \mathrm{~h}$ de exposição sob umidade relativa máxima, avaliada pela metodologia da AOAC. São Paulo, 1992.

\begin{tabular}{lll} 
CARREADORES & \multicolumn{2}{c}{$\begin{array}{c}\text { ATIVIDADE ESPORICIDA* } \\
1^{\text {a }} \text { Subcultura } 2^{\text {a Subcultura }}\end{array}$} \\
\hline Sem crescimento & $120 / 120$ & $120 / 120$ \\
Com crescimento & $0 / 120$ & $0 / 120$
\end{tabular}

Tabela 3 - Atividade esporicida das pastilhas de paraformaldeído a $3 \%$ reutilizadas 47 vezes sobre esporos de Clostridium sporogenes à temperatura de $50^{\circ} \mathrm{C}$ por $4 \mathrm{~h}$ de exposição sob umidade relativa máxima, avaliada pela metodologia da AOAC. São Paulo, 1992.

\section{CARREADORES ATIVIDADE ESPORICIDA*}

1a Subcultura 2a Subcultura

$\begin{array}{lll}\text { Sem crescimento } & 116 / 120 & 110 / 120 \\ \text { Com crescimento } & 4 / 120 & 9 / 120 \\ \text { Com contaminação } & 0 / 120 & 1 / 120\end{array}$

Os resultados dos testes microbiológicos evidenciam que as pastilhas de paraformaldeído a $3 \%$ submetidas a 47 reutilizações nas condições de esterilização de $50^{\circ} \mathrm{C}$ por $4 \mathrm{~h}$, sob umidade relativa máxima, não apresentam atividade esterilizante reconhecida pela metodologia utilizada, apesar de terem mostrado uma atividade $100 \%$ eficaz em relação a um dos microrganismos testes, o Bacillus subtilis,

Os esporos do Clostridium sporogenes apresentaram maior resistência ao formaldeído gasoso que os esporos do Bacillus subtilis, ao contrário dos dados observados por pesquisas de Mecke (1984).

Os resultados dos testes microbiológicos, confrontados com os dos testes físico-químicos apresentados, concordam com a idéia bem estabelecida de que apenas a análise química dos agentes biocidas não fornece informações suficientes para a avaliação da sua ação antimicrobiana, uma vez que esta não é propriedade única da composição química, sendo fortemente afetada por condições físicoquímicas. Embora o ensaio químico demonstre com precisão a presença do princípio ativo, é amplamente reconhecido que os testes microbiológicos são necessários e indicados na avaliação dos agentes esterilizantes, permitindo verificar se o produto realmente atinge a letalidade microbiana. Diante desses resultados, refutar simplesmente a possibilidade de reutilizar as pastilhas de paraformaldeído, não se constituía em medida racional pois as 47 reutilizações foram consideradas um número exagerado em vista do que se observa na prática.

Pautado nesse fato e nas recomendações de Shilling (5), onde os autores admitem o uso do mesmo grupo de pastilhas de paraformaldeído por 2 a 3 semanas para a conservação da esterilidade do material não acondicionado, guardado em armários, optou-se por estudar a possibilidade de reutilização das pastilhas de paraformaldeído um número menor de vezes, definindo-se por $\mathbf{1 2}$ reutilizações.

Sendo assim, um novo grupo de pastilhas novas foi submetido a desgastes por 12 exposições a $50^{\circ} \mathrm{C}$ por $4 \mathrm{~h}$ em umidade relativa máxima e em seguida foram realizados os testes microbiológicos frente, exclusivamente, a Clostridium sporogenes, obtendose resultados $100 \%$ satisfatórios, incluindo a reincubação após o choque térmico.

\section{CONCLUSÕES}

Diante dos resultados apresentados fundamentados na metodologia oficial, preconizada pelo Ministério da Saúde que adota a técnica daAssociation of Official Analytical Chemists (AOAC) (13) utilizada neste estudo, pôde-se concluir que:

- as pastilhas de paraformaldeído demonstraram ação esterilizante em até 12 ciclos de reutilizações nas condições de uso preconizada por Graziano(8);

- apesar dos ensaios físico-químicos das pastilhas, após 47 reutilizações, terem apresentado indícios de liberação de formaldeído gasoso equivalente aos teores liberados pelas pastilhas novas, os testes microbiológicos não validaram a sua ação 


\section{REFERÊNCIAS BIBLIOGRÁFICAS}

(1) Ministério da Saúde e do Trabalho e Emprego. Portaria Interministerial 482 de 16 de abril de 1999. Diário Oficial da União, Brasília, 19 ago. 1999, secção I, p.15.

(2) Graziano KU, Silva A, Bianchi ERF. Métodos de proteção antiinfecciosa. In: Fernandes AT. Infecção hospitalar e suas interfaces na área da saúde. São Paulo: Atheneu; 2000, p.266308.

(3) Crèmieux A, Fleurette J. Methods of testing desinfectants. In: Block SS. Desinfection, sterilization and preservation. 3 ed. Philadelphia, Lea \& Febiger; 1983. p.918- 45.

(4) Salzano SDT. Estudo sobre a ação do parafórmico nas bactérias em forma esporulada. Rev Esc Enferm USP 1968; $2(2): 46-57$.

5) Shilling B, Wigert $H$, Weufffen $W$, Dobeberkau HJ. Use of paraformaldehyde tablets for bacterial count redution desinfection, cold sterilization and sterile preservation of medical instruments. Pharmazie 1982; 37(7):518-21.

(6) Martindale W. The extra farmacopeia. 29ed. London: The Pharmacentical Press; 1972. p. 961-2. Mecke P Desinfection and sterization of thermolabile instruments with gaseous formaldehyde. Zbl. Bakteriol. Mikrobiol. Hyg. (B) 1984; 179(6):529-43,

(7) Cunha MC, Almeida GV, Mimica IM. Uso do paraformaldeído como método de esterilização. Arq Bras Oftal 1988; 5 (4):17880.

(8) Graziano, KU. Avaliação da atividade esterilizante do paraformaldeído. [dissertação] São Paulo (SP): Escola de Enfermagem, Universidade de São Paulo; 1989

(9) Brasil. Portaria n. 67 de 21 de fevereiro de 1985. Dispõe sobre "Normas complementares específicas para registro de saneantes domissanitários com ação antimicrobiana. Diário Oficial da União, Brasília, 27 fev. 1985. Seção 1, p.3180-4.

(10) Hennebert P, Gillardt $\boldsymbol{J}$, Roland M. A new method for gaseous formaldehyde sterilization. SPT Pharma 1986; 2(6):536-42.

(11) Society of Japanese Pharmacopeia. The pharmacopeia of Japan. 11 ed. Yakuji, 1986.

(12) United States Pharmacopeia. 22.ed. Rockville: United States Pharmacopeial Covetio, 1990.

(13) Association of Official Analytical Chemists. Official method of anlysis of the Association of Official Analytical Chemists. 15.ed. Washington; 1995. p.65-77: Desinfectants. 